ERRATUM

doi:10.1038/nature13142

\title{
Erratum: Global carbon dioxide emissions from inland waters
}

Peter A. Raymond, Jens Hartmann, Ronny Lauerwald, Sebastian Sobek, Cory McDonald, Mark Hoover, David Butman, Robert Striegl, Emilio Mayorga,

Christoph Humborg, Pirkko Kortelainen, Hans Dürr, Michel Meybeck, Philippe Ciais \& Peter Guth

Nature 503, 355-359 (2013); doi:10.1038/nature12760

In Fig. 1a of this Article, the highest value on the colour scale should be 11,772 instead of 1,772 . This has been corrected in the HTML and PDF versions of the paper online. 